\title{
Comparing outcomes of donation after cardiac death versus donation after brain death in liver transplant recipients with hepatitis C: A systematic review and meta-analysis
}

\author{
Malcolm Wells MD MSc${ }^{1}$, Kris Croome MD MS², Toni Janik MLIS AHIP3, \\ Roberto Hernandez-Alejandro $\mathrm{MD}^{2}$, Natasha Chandok MD MPH${ }^{1}$
}

\begin{abstract}
M Wells, K Croome, T Janik, R Hernandez-Alejandro, N Chandok. Comparing outcomes of donation after cardiac death versus donation after brain death in liver transplant recipients with hepatitis C: A systematic review and meta-analysis. Can J Gastroenterol Hepatol 2014;28(2):103-108.
\end{abstract}

BACKGROUND: Liver transplantation (LT) using organs donated after cardiac death (DCD) is increasing due, in large part, to a shortage of organs. The outcome of using DCD organs in recipients with hepatits $\mathrm{C}$ virus (HCV) infection remains unclear due to the limited experience and number of publications addressing this issue.

OBJECTIVE: To evaluate the clinical outcomes of DCD versus donation after brain death (DBD) in HCV-positive patients undergoing LT. METHODS: Studies comparing DCD versus DBD LT in HCV-positive patients were identified based on systematic searches of seven electronic databases and multiple sources of gray literature.

RESULTS: The search identified 58 citations, including three studies, with 324 patients meeting eligibility criteria. The use of DCD livers was associated with a significantly higher risk of primary nonfunction (RR 5.49 [95\% CI 1.53 to 19.64]; $\mathrm{P}=0.009 ; \mathrm{I}^{2}=0 \%$ ), while not associated with a significantly different patient survival (RR 0.89 [95\% CI 0.37 to 2.11]; $\mathrm{P}=0.79 ; \mathrm{I}^{2}=51 \%$ ), graft survival (RR 0.40 [95\% CI 0.14 to 1.11]; $\mathrm{P}=0.08 ; \mathrm{I}^{2}=34 \%$ ), rate of recurrence of severe $\mathrm{HCV}$ infection (RR 2.74 [95\% CI 0.36 to 20.92]; $\mathrm{P}=0.33 ; \mathrm{I}^{2}=84 \%$ ), retransplantation or liver disease-related death (RR 1.79 [95\% CI 0.66 to 4.84]; $\mathrm{P}=0.25$; $\left.\mathrm{I}^{2}=44 \%\right)$, and biliary complications.

CONCLUSIONS: While the literature and quality of studies assessing DCD versus DBD grafts are limited, there was significantly more primary nonfunction and a trend toward decreased graft survival, but no significant difference in biliary complications or recipient mortality rates between DCD and DBD LT in patients with HCV infection. There is insufficient literature on the topic to draw any definitive conclusions.

Key Words: Biliary complications; Donation after cardiac death; Hepatitis C; Liver transplantation; Outcomes
Comparer les issues du don d'organe après un décès cardiaque plutôt qu'après un décès cérébral chez des greffés du foie atteints d'hépatite $\mathrm{C}$ : une analyse systématique et une méta-analyse

HISTORIQUE : La transplantation hépatique (TH) au moyen de dons d'organes après un décès cardiaque (DDCa) augmente, en grande partie à cause d'une pénurie d'organes. Les issues de l'utilisation d'organes DDCa chez des greffés atteints d'une infection par le virus de l'hépatite $\mathrm{C}$ (VHC) demeure nébuleux, en raison de l'expérience limitée et du peu de publications sur la question.

OBJECTIF : Évaluer les issues cliniques du DDCa par rapport au don d'organe après un décès cérébral (DDCé) chez des patients positifs au VHC qui ont subi une TH.

MÉTHODOLOGIE : Les chercheurs ont extrait les études comparant la TH DDCa et la TH DDCé chez des patients positifs au VHC au moyen de recherches systématiques menées dans sept bases de données électroniques et de multiples sources de non publiées.

RÉSULTATS : La recherche a permis d'extraire 58 citations, dont trois études comptant 324 patients qui respectaient les critères d'admissibilité. Le recours à des foies DDCa s'associait à un risque significativement plus élevé de non-fonction primaire (RR 5,49 [95 \% IC 1,53 à 19,64]; $\left.\mathrm{P}=0,009 ; \mathrm{I}^{2}=0 \%\right)$, mais la différence n'était pas significative sur le plan de la survie des patients (RR 0,89 [95 \% IC 0,37 à 2,11]; $\mathrm{P}=0,79$; $\mathrm{I}^{2}=51 \%$ ), de la survie après la transplantation (RR 0,40 [95\% IC $0,14$ à 1,11$\left.] ; \mathrm{P}=0,08 ; \mathrm{I}^{2}=34 \%\right)$, du taux de récurrence de grave infection par le VHC (RR 2,74 [95 \% IC 0,36 à 20,92]; P=0,33; $\mathrm{I}^{2}=84 \%$ ), des nouvelle transplantations ou des décès liés à l'insuffisance hépatique (RR 1,79 [95 \% IC 0,66 à 4,84]; P=0,25; I²=44 \%) et des complications biliaires.

CONCLUSIONS : Les publications et la qualité des études évaluant les TH DDCa par rapport aux TH DDCé sont limitées. Toutefois, on observait une non-fonction primaire beaucoup plus importante et une tendance vers une diminution de la survie après la transplantation, mais aucune différence significative sur le plan des complications biliaires ou des décès chez les greffés infectés par le VHC après un DDCa ou un DDCé. Les publications sont insuffisantes pour qu'il soit possible de tirer des conclusions définitives.

have the potential to help address the disparity between organ availability and the number of patients awaiting LT, their use has been associated with higher rates of graft failure and biliary complication, particularly ischemic cholangiopathy, compared with donation after brain death (DBD) allografts $(5,6)$.

Hepatitis $\mathrm{C}$ virus (HCV) infection is currently a leading indication for LT, constituting approximately $30 \%$ to $50 \%$ of all transplants (7-10). Previous studies have suggested that HCV-positive recipients iver transplantation (LT) is a life-saving modality for treating
well-selected patients with acute liver failure, end-stage liver dis-
ease, certain metabolic disorders and early hepatocellular carcinoma.
The current practice of LT is limited by the significant disparity
between organ availability and the number of patients awaiting trans-
plantation. Donation after cardiac death (DCD) has become a signifi-
cant source of transplantable organs in an attempt to expand the
donor pool and increase organ supply $(1-4)$. While DCD allografts

${ }^{1}$ Department of Medicine; ${ }^{2}$ Department of Surgery, Schulich School of Medicine and Dentistry, Western University, London; ${ }^{3}$ Hotel Dieu Grace Hospital,

Windsor, Ontario

Correspondence: Dr Natasha Chandok, Department of Medicine, Schulich School of Medicine and Dentistry, Western University, 339 Windermere Road,

PO Box 5339, London, Ontario N6A 5A5. Telephone 519-663-3002, fax 519-663-3858, e-mail nchandok@uwo.ca

Received for publication October 3, 2013. Accepted October 13, 2013 
of DBD LT have worse outcomes than HCV-negative recipients, largely due to a more rapid and severe manner of recurrence of their HCV-related liver disease $(9,11)$. Recurrence of HCV after LT is universal, with $20 \%$ to $40 \%$ of patients progressing to cirrhosis within five years of LT (12). Previous studies have shown that liver allografts from extended-criteria donors, such as those with advanced age, are at an increased risk of earlier and more severe HCV recurrence; this has deleterious impact on both patient and graft outcomes (13-16). It has also been suggested that organ cold/warm ischemia is a risk factor for increased severity of recurrence of HCV after LT. DCD organs experience warm ischemic injury not characteristic of DBD donors because of hypoperfusion and hypoxia during the agonal period of time of withdrawal of life support (11). It has, therefore, been theorized that HCV patients receiving DCD allografts may be at an increased risk for graft injury and accelerated HCV recurrence. Despite this theoretical risk, the literature investigating the outcomes of HCV-positive patients receiving DCD allografts is scant and conflicting reports have been published.

Tao et al (17) performed a retrospective matched control trial of $111 \mathrm{HCV}$-positive patients (37 receiving DCD LT and 74 matched controls receiving DBD LT). Although the two groups had similar donor and recipient characteristics, immunosuppression regimens, rates of acute cellular rejection and HCV profiles, the patients receiving DCD LT had a higher incidence of primary nonfunction (19\% versus $3 \% ; \mathrm{P}=0.006)$ and significantly higher peak aspartate aminotransferase levels compared with DBD subjects. Although the survival rates were not significantly different, DCD LT recipients had lower one- and five-year survival rates $(83 \%$ and $69 \%$ versus $84 \%$ and $78 \%$, respectively; $\mathrm{P}=0.75)$ and graft survival rates $(70 \%$ and $61 \%$ versus $82 \%$ and $74 \%$, respectively; $\mathrm{P}=0.24$ ). A total of 314 liver biopsies were performed; mixed modelling analysis showed that fibrosis progression rates were similar for the two groups ( 0.6 fibrosis units/year according to the Ishak modified staging system). The rates of severe HCV recurrence (retransplantation or death due to recurrent $\mathrm{HCV}$ and/or the development of stage $4 / 6$ fibrosis or worse within two years) were not significantly different (three [8\%] DCD patients versus 11 [15\%] DBD patients; $\mathrm{P}=0.38$ ). Cytomegalovirus infection (HR 7.9 [95\% CI 2.1 to 28.9]; $\mathrm{P}=0.002$ ) and acute cellular rejection ( $\mathrm{HR}$ 6.2 [95\% CI 2.0 to 19.7]; $\mathrm{P}=0.002$ ) were the only independent risk factors for severe recurrence.

Taner et al (18) performed a retrospective analysis of $77 \mathrm{HCV}$ positive patients who received DCD liver grafts and 77 matched HCVpositive patients who received DBD liver grafts. There were no differences in one-, three- and five-year patient or graft survival rates among the groups. Multivariate analysis showed that the Model for End-Stage Liver Disease score (HR 1.037 [95\% CI 1.006 to 1.069 ]; $\mathrm{P}=0.018]$ ) and post-transplant cytomegalovirus infection (HR 3.367 [95\% CI 1.493 to 7.593]; $\mathrm{P}=0.003$ ) were significant factors for graft loss. A comparison of five-year protocol biopsy samples for fibrosis progression in HCV-positive patients post-transplant did not show a difference between DCD and DBD grafts. The authors concluded that DCD liver graft utilization does not cause untoward effects on disease progression or patient and graft survival compared with DBD liver grafts in HCV-positive patients.

Hernandez-Alejandro et al (19) performed a retrospective, matchedcontrol trial evaluating 17 recipients with $\mathrm{HCV}$ who received a DCD graft and a matched group of $42 \mathrm{HCV}$ recipients transplanted with a DBD graft. They found a statistically significant decrease in graft survival in HCV-positive patients undergoing DCD transplant (73\%) compared with DBD transplant (93\%) $(\mathrm{P}=0.01)$. There was a statistically significant increase in $\mathrm{HCV}$ recurrence at three months $(76 \%$ versus $16 \%$; $\mathrm{P}=0.005)$ and severe $\mathrm{HCV}$ recurrence within the first year (47\% versus $10 \%)$ in the DCD group ( $\mathrm{P}=0.004)$. The authors concluded that HCV recurrence is more severe and progresses more rapidly in HCV recipients who receive DCD grafts compared with those who receive DBD grafts. DCD LT in HCV recipients is associated with a higher rate of graft failure compared with those who receive DBD grafts.
The objective of the present study was to perform a systematic review and meta-analysis of studies comparing clinical outcomes of DCD versus DBD orthotopic LT in patients with HCV. The primary outcomes of interest were patient survival rates, graft survival rates, recurrence of severe $\mathrm{HCV}$, primary nonfunction, acute cellular rejection, biliary strictures (diffuse or localized, anastomotic or nonanastomotic), biliary leaks and vascular complications (hepatic artery stenosis, hepatic artery thrombosis, portal vein thrombosis).

\section{Primary objectives}

\section{METHODS}

To compare one-year patient and graft survival rates in recipients transplanted for HCV with DCD versus DBD grafts; and to compare one-year patient and graft survival rates in recipients with versus without HCV undergoing DCD versus DBD LT.

\section{Secondary objectives}

To determine whether DCD LT compared with DBD LT in HCVpositive patients increases rates of primary nonfunction, acute cellular rejection, biliary strictures (diffuse or localized, anastomotic or nonanastomotic), biliary leaks or vascular complications (hepatic artery stenosis, hepatic artery thrombosis portal vein thrombosis).

\section{Eligibility criteria}

Inclusion criteria were studies that compared DCD versus DBD LT in patients with HCV, as well as DCD LT in patients with and without $\mathrm{HCV}$; and studies that evaluated adult recipients (age $\geq 18$ years) who underwent primary LT. To be included, studies had to include at least one of the prespecified outcomes. There was no limitation on randomized control trials and no restrictions on language. Results duplicated in multiple articles were included only once.

\section{Information sources}

A clinical librarian experienced in conducting systematic reviews in the health care field assisted with the literature search. The following electronic databases were searched to March 29, 2012: MEDLINE, Cochrane Database of Systematic Reviews (Cochrane Reviews); Database of Abstracts of Reviews of Effects (Other Reviews); Cochrane Central Register of Controlled Trials (Clinical Trials); Cochrane Methodology Register (Methods Studies); Health Technology Assessment Database (Technology Assessments); and the NHS Economic Evaluation Database (Economic Evaluations). Relevant articles from incompletely and nonpublished literature were identified by consulting with experts in the field. Searches were supplemented by reviewing the reference lists of all citations that met inclusion criteria by screening the first 50 citations in the 'See related articles' function on PubMed of the included studies, and by searching www.clinicaltrials.gov for relevant trials. Corresponding authors were e-mailed when additional information was needed.

\section{Study selection}

Two investigators (MW and NC) independently screened the title and abstract of the citations. If either investigator believed that a citation was relevant, it was marked for full-text retrieval. Two investigators independently evaluated the retrieved full-text articles for eligibility. Cohen's kappa statistic was used to quantify agreement between the investigators. Disagreements were resolved by discussion, and a third investigator $(\mathrm{KC})$ was consulted in case of impasse.

\section{Data collection}

Two reviewers independently abstracted the data from included trials using a data collection form. Any disagreement in the abstracted data between the two reviewers was resolved by consensus. A third investigator resolved outstanding disagreements. In cases in which the data were incomplete or unclear, the study authors were contacted. 


\section{Data items}

The following items were abstracted from the articles: demographic data of the study population and comparison group including age and sex; DCD versus DBD liver donations; features of the study design including allocation concealment, blinding, intention-to-treat analysis, number of patients lost to follow-up, rate of premature termination and funding source; the outcome measures of patient survival rate and graft survival rate; rates of primary nonfunction, acute cellular rejection, biliary strictures (diffuse or localized, anastomotic or nonanastomotic), biliary leaks, ischemic cholangiography, vascular complications (hepatic artery stenosis, hepatic artery thrombosis, portal vein thrombosis), HCV recurrence and retransplantation/liverrelated death.

\section{Risk of bias}

The risk of bias on a study level was assessed by determining the adequacy of the method of randomization, allocation concealment, blinding of the trial participants, care providers and outcome assessors. Also assessed were whether the trial was terminated prematurely, whether the analysis was an intention-to-treat and the funding source.

The Grading of Recommendations, Assessment, Development and Evaluation approach (20) was used to characterize the risk of bias for each of the outcomes that had available data.

\section{Statistical analysis}

The meta-analysis was performed using the Cochrane Collaboration and the Quality of Reporting of Meta-analyses (QUORUM) guidelines. Statistical analyses were performed using Review Manager 5 (www.cochrane.org/). The RR was used as a summary measure of efficacy for dichotomous data and the mean difference between groups for continuous data to summarize the outcomes for patients treated with duct-to-duct versus Roux-en-Y loop anastomosis. For all RRs and mean differences, a 95\% CI was reported. All analyses were conducted on an intention-to-treat basis.

\section{Synthesis of results}

Results were pooled using a Mantel-Haenszel random-effects model for dichotomous outcomes and mean difference for continuous outcomes. Statistical heterogeneity was evaluated using the $\mathrm{I}^{2}$ statistic. An $\mathrm{I}^{2}$ value of $0 \%$ to $25 \%, 25 \%$ to $50 \%$ and $>50 \%$ were considered to be indicative of low, moderate and high heterogeneity, respectively.

\section{Risk of publication bias}

Funnel plots were used to assess the risk of publication bias across trials for all outcome measures.

\section{Study selection}

\section{RESULTS}

Fifty-eight citations were screened, of which 15 were selected for fulltext retrieval. Of these, three articles (17-19) fulfilled eligibility criteria and were, thus, selected (Figure 1).

There was no disagreement regarding eligibility of full-text articles (Cohen's kappa $=1.00)$, and consensus was reached among all authors on inclusion and exclusion of all articles.

Twelve of the retrieved articles were excluded due to the absence of a comparison of DCD versus DBD liver donation in patients with $\mathrm{HCV}$ $(n=10)(8,21-29)$ or the article was an editorial $(n=1)(30)$.

\section{Study characteristics}

A total of 324 study participants in three trials comparing DCD versus DBD liver transplantation in HCV-positive patients. Study characteristics are included in Table 1.

\section{Risk of bias within trials}

The included trials had a high risk of bias. All three trials were retrospective analyses performed at single centres. There was no blinding and concealment.

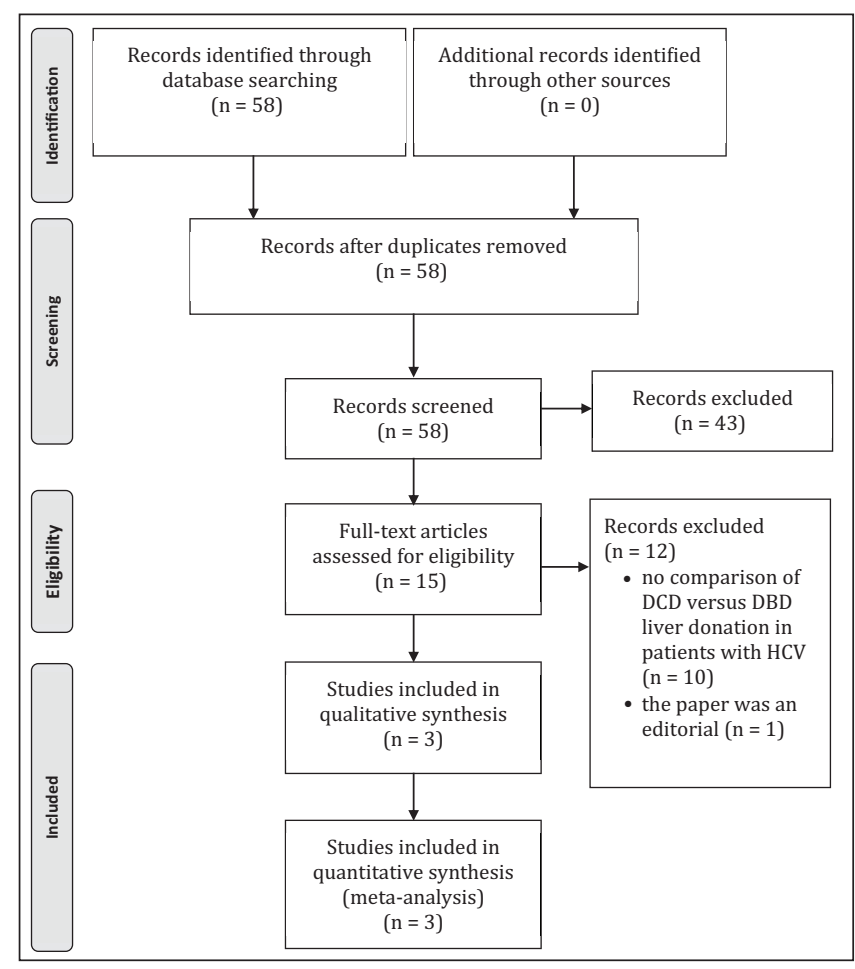

Figure 1) Study selection. DBD Donation after brain death; DCD Donation after cardiac death; HCV Hepatitis C virus

Risk of bias across trials

The funnel plots of the RR for all outcomes did not show evidence of publication bias.

\section{Recipient survival}

Compared with DBD, orthotopic LT with a DCD liver was not associated with a significantly decreased patient survival (three studies; risk ratio 0.89 [95\% CI 0.37 to 2.11]; $\mathrm{P}=0.79 ; \mathrm{I}^{2}=51 \%$ ) (Figure 2). Heterogeneity was potentially explained by differences in length of follow-up. The overall quality of evidence was low (20).

\section{Graft survival}

DCD LT trended toward, but was not significantly associated with, a decrease in graft survival $(\mathrm{n}=2$; RR 0.40 [95\% CI 0.14 to 1.11$]$; $\mathrm{P}=0.08$; $\mathrm{I}^{2}=34 \%$ ) (Figure 3 ). Heterogeneity was potentially explained by differences in length of follow-up. The overall quality of evidence was low (20).

\section{Biliary complications}

The risk of biliary leaks was not statistically significantly higher $(n=2$; risk ratio 2.22 [95\% CI 0.42 to 11.88$] ; \mathrm{P}=0.35 ; \mathrm{I}^{2}=35 \%$ ) (Figure 4 ) in patients receiving a DCD versus a DBD LT. The level of heterogeneity was explained by length of follow-up, differences in the definition of biliary leak, and differences in postoperative imaging or investigations for leak. The overall quality of evidence was low (20).

Biliary strictures were not statistically different ( $n=2$; RR $1.15[95 \%$ CI 0.59 to 2.26]; $\mathrm{P}=0.68 ; \mathrm{I}^{2}=0 \%$ ) (Figure 4 ) in patients receiving a DCD versus a DBD LT. The quality of evidence was low (20).

Patients receiving LT from a DCD versus a DBD did not have a significantly increased risk of ischemic cholangiopathy $(n=3$; RR 6.67 [95\% CI 0.84 to 52.66]; $\mathrm{P}=0.07 ; \mathrm{I}^{2}=35 \%$ ) (Figure 4). The quality of evidence was low (20).

\section{Recurrence of HCV infection}

Recurrence of HCV was not significantly different in patients receiving DCD versus DBD LT when patients from two studies were pooled, with a risk ratio of 2.74 (95\% CI 0.36 to $20.92 ; \mathrm{P}=0.33 ; \mathrm{I}^{2}=84 \%$ ) (Figure 5). The overall quality of evidence was low (20). 
TABLE 1

Characteristics of included studies

\begin{tabular}{|c|c|c|c|c|c|c|}
\hline & \multicolumn{2}{|c|}{ Hernandez-Alejandro et al (13), 2011} & \multicolumn{2}{|c|}{ Taner et al (18), 2011} & \multicolumn{2}{|c|}{ Tao et al (17), 2010} \\
\hline & DCD & DBD & DCD & DBD & DCD & DBD \\
\hline Transplantations, $\mathrm{n}$ & 17 & 42 & 77 & 77 & 37 & 74 \\
\hline Age, years, mean \pm SD & $44 \pm 13$ & $46 \pm 9$ & $37.7 \pm 13.5$ & $37.6 \pm 13.2$ & $37.9 \pm 16.4$ & $38.1 \pm 16.2$ \\
\hline Sex, male:female, $n: n$ & $\mathrm{~N} / \mathrm{A}$ & N/A & N/A & N/A & $27: 10$ & $45: 31$ \\
\hline Body mass index, $\mathrm{kg} / \mathrm{m}^{2}$, mean $\pm \mathrm{SD}$ & $N / A$ & $\mathrm{~N} / \mathrm{A}$ & N/A & N/A & $26.6 \pm 5.3$ & $28.3 \pm 9.6$ \\
\hline Height, $\mathrm{cm}$, mean \pm SD & $171.1 \pm 8.5$ & $171.9 \pm 10$ & N/A & N/A & N/A & N/A \\
\hline Donor COD (CVA/trauma/anoxia/other), $\mathrm{n}$ & $10 / 5 / 2 / 0$ & $28 / 6 / 6 / 2$ & $19 / 37 / 18 / 3$ & $37 / 22 / 18 / 0$ & N/A & N/A \\
\hline \multicolumn{7}{|l|}{ Recipient characteristics } \\
\hline Age, years, mean $\pm S D$ & $54.2 \pm 5$ & $48 \pm 10$ & $54.5 \pm 5.9$ & $53.4 \pm 6.0$ & $51 \pm 6.7$ & $51 \pm 6.2$ \\
\hline Sex, male:female, n:n & $15: 2$ & $30: 12$ & 59:18 & $55: 22$ & $31: 6$ & $58: 16$ \\
\hline Hepatitis C genotype $1, \mathrm{n}(\%)$ & $12(70.6)$ & $30(71.4)$ & N/A & N/A & $\mathrm{N} / \mathrm{A}$ & $\mathrm{N} / \mathrm{A}$ \\
\hline
\end{tabular}

COD Cause of death; CVA Cerebral vascular accident; DBD Donation after brain death; DCD Donation after cardiac death; MELD Model for End-stage Liver Disease; N/A Not available

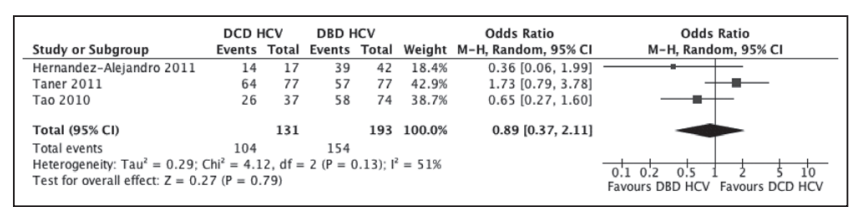

Figure 2) Forest plot of recipient survival. DBD Donation after brain death; DCD Donation after cardiac death; HCV Hepatitis C virus

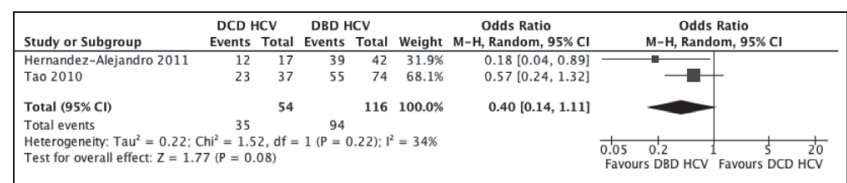

Figure 3) Forest plot of graft survival. DBD Donation after brain death; DCD Donation after cardiac death; HCV Hepatitis C virus

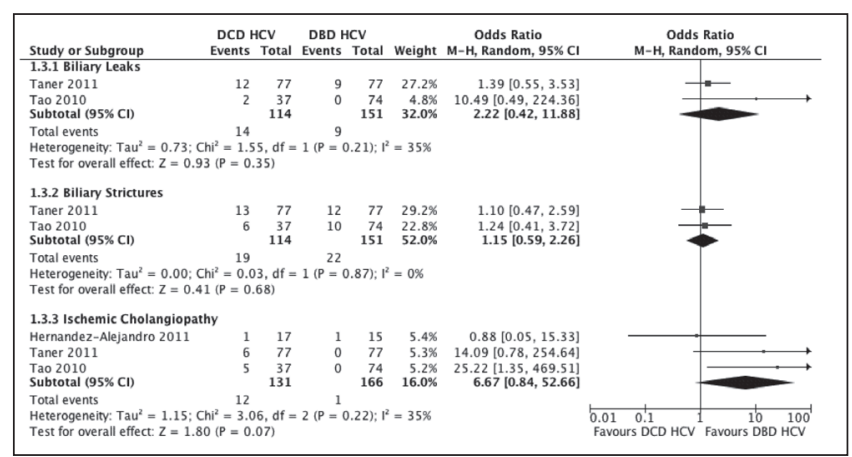

Figure 4) Forest plot of biliary complications. DBD Donation after brain death; DCD Donation after cardiac death; HCV Hepatitis C virus

Transplant liver primary nonfunction

Compared with DBD, LT with a DCD liver was associated with significantly increased primary liver nonfunction (three studies; risk ratio 5.49 [ $95 \%$ CI 1.53 to 19.64]; $\mathrm{P}=0.009 ; \mathrm{I}^{2}=0 \%$ ) (Figure 6). The overall quality of evidence was low (20).

\section{Retransplantation}

DCD LT was not significantly associated with an increased risk of retransplantation (two studies; RR 1.79 [95\% CI 0.66 to 4.84]; $\mathrm{P}=0.25$; $\mathrm{I}^{2}=44 \%$ ) (Figure 7). The overall quality of evidence was low (20).

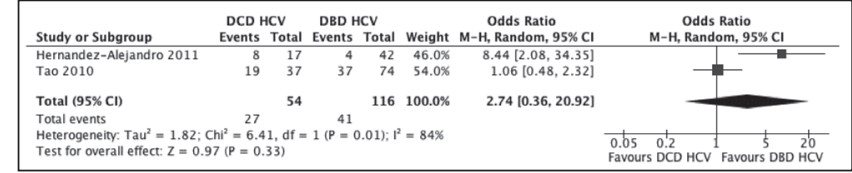

Figure 5) Forest plot of recurrence of hepatitis $\mathrm{C}$ virus (HCV) infection. DBD Donation after brain death; DCD Donation after cardiac death

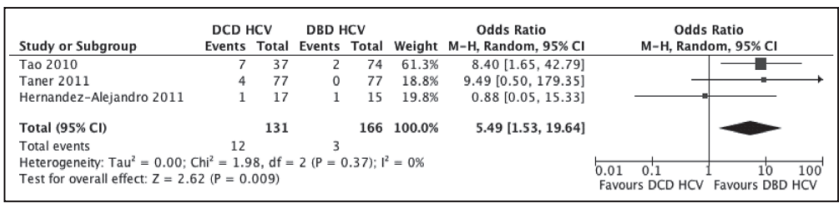

Figure 6) Forest plot of primary nonfunction. DBD Donation after brain death; DCD Donation after cardiac death; HCV Hepatitis C virus

\begin{tabular}{|c|c|c|c|c|c|c|c|c|}
\hline \multirow{3}{*}{$\begin{array}{l}\text { Study or Subgroup } \\
\text { Taner } 2011 \\
\text { Tao } 2010\end{array}$} & \multicolumn{2}{|c|}{$\begin{array}{l}\text { DCD HCV } \\
\text { Events Total }\end{array}$} & \multicolumn{2}{|c|}{$\begin{array}{l}\text { DBD HCV } \\
\text { Events Total }\end{array}$} & \multirow{3}{*}{$\begin{array}{r}\text { Weight } \\
54.8 \% \\
45.2 \%\end{array}$} & \multirow{3}{*}{$\begin{array}{c}\begin{array}{c}\text { Odds Ratio } \\
\text { M-H, Random, } 95 \% \mathrm{Cl}\end{array} \\
1.13[0.43,2.95] \\
3.13[1.00,9.82]\end{array}$} & \multicolumn{2}{|c|}{$\begin{array}{l}\text { Odds Ratio } \\
\mathrm{M}-\mathrm{H} \text {, Random, } 95 \% \mathrm{CI}\end{array}$} \\
\hline & 10 & 77 & 9 & 77 & & & & \\
\hline & 8 & 37 & 6 & 14 & & & & \\
\hline $\begin{array}{l}\text { Total }(95 \% \mathrm{Cl}) \\
\text { Total events }\end{array}$ & & 114 & & & $100.0 \%$ & $1.79[0.66,4.84]$ & & \\
\hline $\begin{array}{l}\text { Heterogeneity: } \text { Tau }^{2} \\
\text { Test for overall effec }\end{array}$ & $\begin{array}{l}0.23 ; C h \\
z=1.14\end{array}$ & $\begin{array}{l}\mathrm{i}^{2}=1.7 \\
(\mathrm{P}=0 .\end{array}$ & & & & & 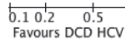 & $\int_{\text {Favours DBD }}^{\frac{1}{2}} \frac{1}{5} 10$ \\
\hline
\end{tabular}

Figure 7) Forest plot of retransplantation. DBD Donation after brain death; DCD Donation after cardiac death; HCV Hepatitis C virus

\section{DISCUSSION AND CONCLUSIONS}

\section{Summary of evidence}

Three trials evaluated DCD versus DBD LT in recipients with HCV infection. The use of DCD livers in HCV-positive recipients was associated with a significant increase in primary nonfunction, but no significant difference in biliary complications, graft survival rates and recipient mortality rates (Table 1 ).

\section{Limitations}

The conclusions that can be drawn from the present systematic review were limited by the small numbers of patients and the retrospective nature of the trials included. Length of follow-up varied substantially among the studies. Techniques and experience also vary among institutions. In addition, there was a lack of histopathological correlation and generalizability of results, in addition to potential selection biases. There were significant differences in rates of HCV recurrence that could, at least partially, be explained by differences in rates of antiviral treatment within the first year post-LT. 
Despite these limitations, there is still value in the current metaanalysis because it is the first study of its kind and contributes to the knowledge base. Published experiences will likely never be prospective or randomized given the nature of transplantation, the complexities of organ allocation and important issues involving medical ethics. Therefore, high-grade evidence for this topic may never emerge.

\section{Implications for clinical practice}

Although significant for limitations, our meta-analysis indicates there is a substantial increase in primary nonfunction and a trend toward a decrease in graft survival, but no significant difference in other important clinical outcomes between DCD and DBD allografts in HCVpositive LT recipients.

Controversy remains in the use of DCD LT in HCV-positive patients. Individually, DCD LT and the presence of HCV have negative impact on patient and graft survival (11). It remains unclear whether the combination of DCD LT and HCV synergistically confers a worse outcome. The two studies that demonstrated no significant difference in patient outcomes with use of DCD LT in HCV-positive patients $(17,18)$ included younger patients than the study that found a significant decrease in graft survival in $\mathrm{HCV}$-positive patients undergoing DCD versus DBD LT (19).

DCD grafts are not contraindicated in well-selected $\mathrm{HCV}$ recipients and this is potentially an underutilized method to expand the donor pool. Over the past 10 years, approximately 700 to 800 patients have died awaiting LT (www.unos.org); DCD LT may be one of many solutions requiring further investigation.

\section{Implications for research}

DCD allografts have become a significant source of transplantable organs in an attempt to bridge the gap between supply and demand in LT. Our meta-analysis indicates an increased number of adverse events (namely primary nonfunction) with DCD allografts in HCV-positive

\section{REFERENCES}

1. de Vera ME, Lopez-Solis R, Dvorchik I, et al. Liver transplantation using donation after cardiac death donors: Long-term follow-up from a single center. Am J Transpl 2009;9:773-81.

2. Grewal HP, Willingham DL, Nguyen J, et al. Liver transplantation using controlled donation after cardiac death donors: An analysis of a large single-center experience. Liver Transpl 2009;15:1028-35.

3. Fujita S, Mizuno S, Fujikawa T, et al. Liver transplantation from donation after cardiac death: A single center experience. Transplantation 2007;84:46-9.

4. Pine JK, Aldouri A, Young AL, et al. Liver transplantation following donation after cardiac death: An analysis using matched pairs. Liver Transpl 2009;15:1072-82.

5. Foley DP, Fernandez LA, Leverson G, et al. Donation after cardiac death: The University of Wisconsin experience with liver transplantation. Ann Surg 2005;242:724-31.

6. Chan EY, Olson LC, Kisthard JA, et al. Ischemic cholangiopathy following liver transplantation from donation after cardiac death donors. Liver Transpl 2008;14:604-10.

7. Watt K, Veldt B, Charlton M. A practical guide to the management of HCV infection following liver transplantation. Am J Transpl 2009;9:1707-13.

8. Uemura T, Ramprasad V, Hollenbeak CS, Bezinover D, Kadry Z. Liver transplantation for hepatitis $\mathrm{C}$ from donation after cardiac death donors: An analysis of OPTN/UNOS data. Am J Transpl 2012;12:984-91.

9. Forman LM, Lewis JD, Berlin JA, Feldman HI, Lucey MR. The association between hepatitis $\mathrm{C}$ infection and survival after orthotopic liver transplantation. Gastroenterology 2002;122:889-96.

10. Berenguer M, Lopez-Labrador FX, Wright TL. Hepatitis C and liver transplantation. J Hepatol 2001;35:666-78.

11. Harring TR, Nguyen NT, Cotton RT, et al. Liver transplantation with donation after cardiac death donors: A comprehensive update. J Surg Res 2012;178:502-11.

12. Neumann UP, Berg T, Bahra M, et al. Long-term outcome of liver transplants for chronic hepatitis C: A 10-year follow-up. Transplantation 2004;77:226-31. patients and a trend toward decreased graft survival, but no significant decrease in patient survival.

Ideally, DBD allografts appear to be better suited to HCV-positive patients; however, organ availability necessitates the use of DCD allografts. The quality of evidence in the three included articles was low; a randomized control trial with protocolized liver biopsies would be ideal. However, this is not feasible because recipients could not be randomized because the process of listing recipients is complex and not amenable to a randomized control trial. In the absence of a trial, more observational, prospective and multicentre data are needed.

DISCLOSURES: All authors declare no support from any organization for the submitted work; no financial relationships with any organizations that may have an interest in the submitted work in the previous three years; and no other relationships or activities that could appear to have influenced the submitted work.

AUTHOR CONTRIBUTIONS: All authors contributed to the concept and design, and provided intellectual content of critical importance to this work. Dr Wells, Ms Janik and Dr Chandok performed the electronic literature search and manual search for potential articles. Dr Wells and Dr Chandok retrieved citations, reviewed full text papers and abstracted the data. All authors participated in the analysis and interpretation. All authors approved the final version of this article.

FUNDING: Supported by Western University Department of Medicine Program of Experimental Medicine (POEM) Research Award.

ACKNOWLEDGEMENTS: The authors acknowledge Valerie Kowalkovski of the University Hospital Library, London Health Sciences Centre for her help in retrieving the articles selected for full-text retrieval.
13. Hernadez-Alejandro R, Wall W, Jevnikar A, et al. Organ donation after cardiac death: Donor and recipient outcomes after the first three years of the Ontario experience. Can J Anaesthes 2011;58:599-605.

14. Furukawa H, Taniguchi M, Fujiyoshi M, Oota M. Experience using extended criteria donors in first 100 cases of deceased donor liver transplantation in Japan. Transpl Proc 2012;44:373-5.

15. Cameron A, Busuttil RW. AASLD/ILTS transplant course: Is there an extended donor suitable for everyone? Liver Transpl 2005(11 Suppl 2):S2-5.

16. Baccarani U, Adani GL, Toniutto P, et al. Liver transplantation from old donors into HCV and non-HCV recipients. Transpl Proc 2004;36:527-8.

17. Tao R, Ruppert K, Cruz RJ Jr, et al. Hepatitis C recurrence is not adversely affected by the use of donation after cardiac death liver allografts. Liver Transpl 2010;16:1288-95.

18. Taner CB, Bulatao IG, Keaveny AP, et al. Use of liver grafts from donation after cardiac death donors for recipients with hepatitis $\mathrm{C}$ virus. Liver Transpl 2011;17:641-9.

19. Hernandez-Alejandro R, Croome KP, Quan D, et al. Increased risk of severe recurrence of hepatitis $\mathrm{C}$ virus in liver transplant recipients of donation after cardiac death allografts. Transplantation 2011;92:686-9.

20. Guyatt GH, Oxman AD, Vist GE, et al. GRADE: An emerging consensus on rating quality of evidence and strength of recommendations. BMJ 2008;336:924-6.

21. Allam N, Al Saghier M, El Sheikh Y, et al. Clinical outcomes for Saudi and Egyptian patients receiving deceased donor liver transplantation in China. Am J Transpl 2010;10:1834-41.

22. Chen T, Jia H, Li J, Chen X, Zhou H, Tian H. New onset diabetes mellitus after liver transplantation and hepatitis $\mathrm{C}$ virus infection: Meta-analysis of clinical studies. Transpl Int 2009;22:408-15.

23. Feng S, Goodrich NP, Bragg-Gresham JL, et al. Characteristics associated with liver graft failure: The concept of a donor risk index. Am J Transpl 2006;6:783-90. 
24. Grewal HP, Willingham DL, Nguyen J, et al. Liver transplantation using controlled donation after cardiac death donors: An analysis of a large single-center experience. Liver Transpl 2009;15:1028-35.

25. Hong JC, Yersiz H, Kositamongkol P, et al. Liver transplantation using organ donation after cardiac death: A clinical predictive index for graft failure-free survival. Arch Surg 2011;146:1017-23.

26. Mathur AK, Heimbach J, Steffick DE, Sonnenday CJ, Goodrich NP, Merion RM. Donation after cardiac death liver transplantation: Predictors of outcome. Am J Transpl 2010;10:2512-9.

27. Ortiz J, Feyssa EL, Parsikia A, et al. Severe hepatitis C virus recurrence is nearly universal after donation after cardiac death liver transplant. Exp Clin Transpl 2011;9:105-12.
28. Watt KD, Pedersen RA, Kremers WK, Heimbach JK, Charlton MR. Evolution of causes and risk factors for mortality post-liver transplant: Results of the NIDDK long-term follow-up study. Am J Transpl 2010;10:1420-7.

29. Xirouchakis E, Triantos C, Manousou P, et al. Pegylated-interferon and ribavirin in liver transplant candidates and recipients with HCV cirrhosis: Systematic review and meta-analysis of prospective controlled studies. J Viral Hepat 2008;15:699-709.

30. Garcia-Valdecasas JC. DCD donors: A unique source to significantly increase organ donation. J Hepatol 2011;55:745-6.

 


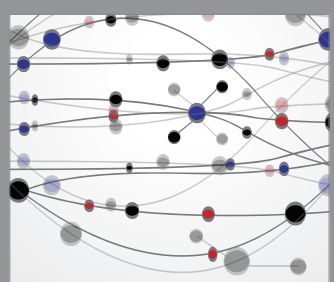

The Scientific World Journal
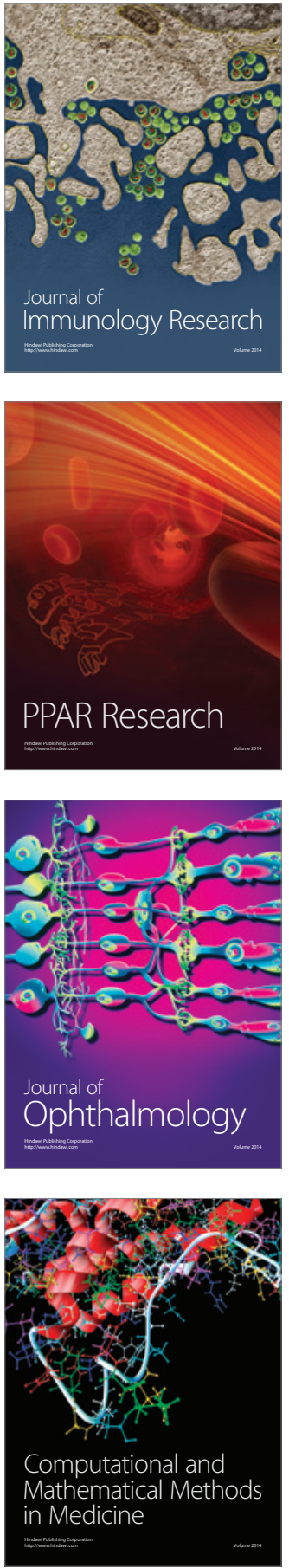

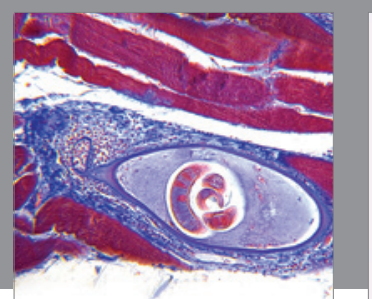

Gastroenterology Research and Practice

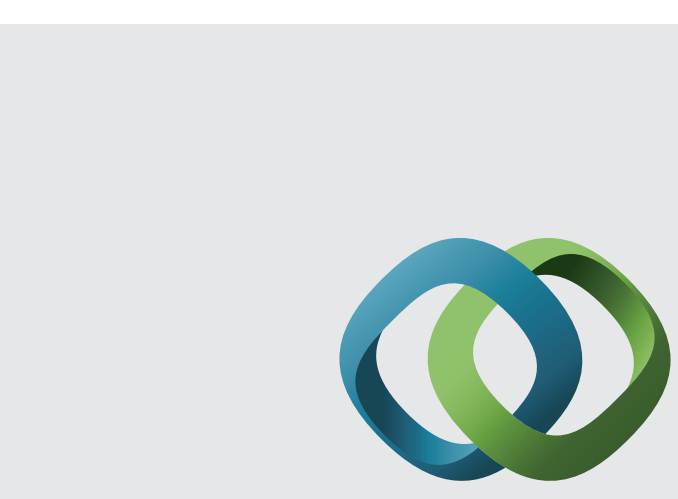

\section{Hindawi}

Submit your manuscripts at

http://www.hindawi.com
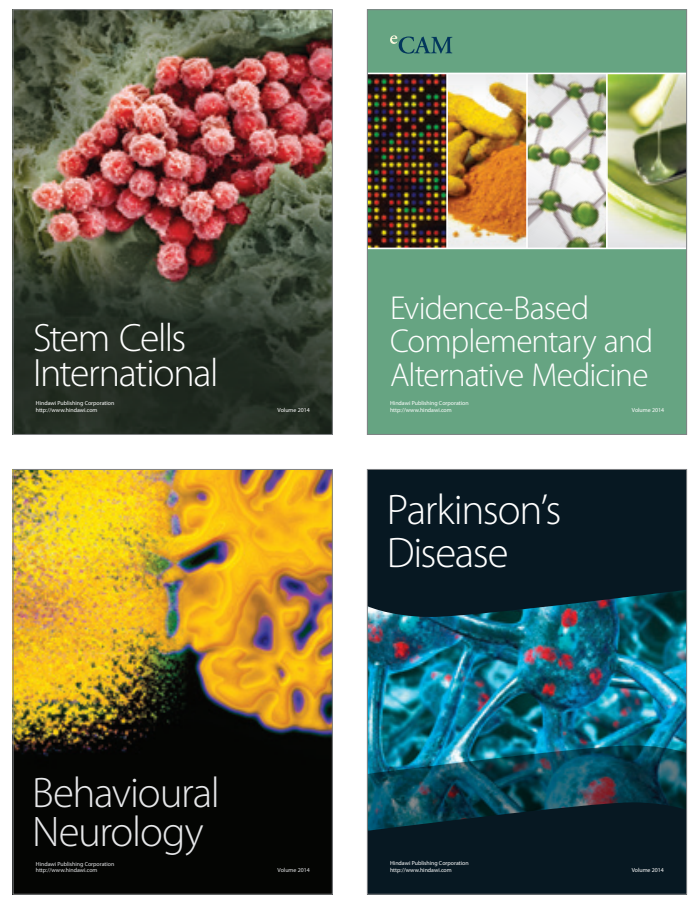
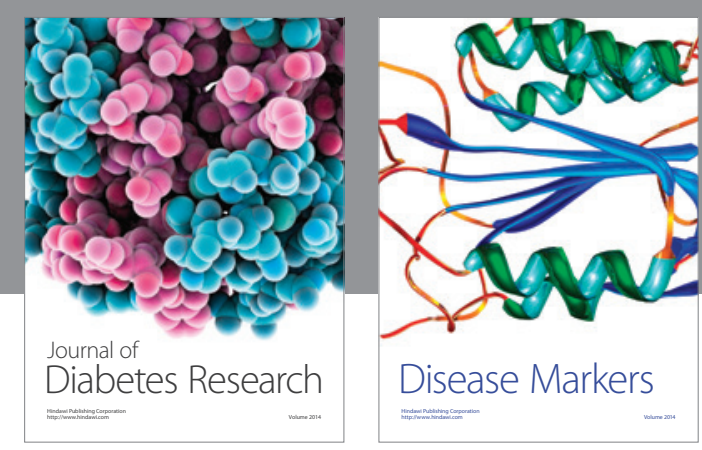

Disease Markers
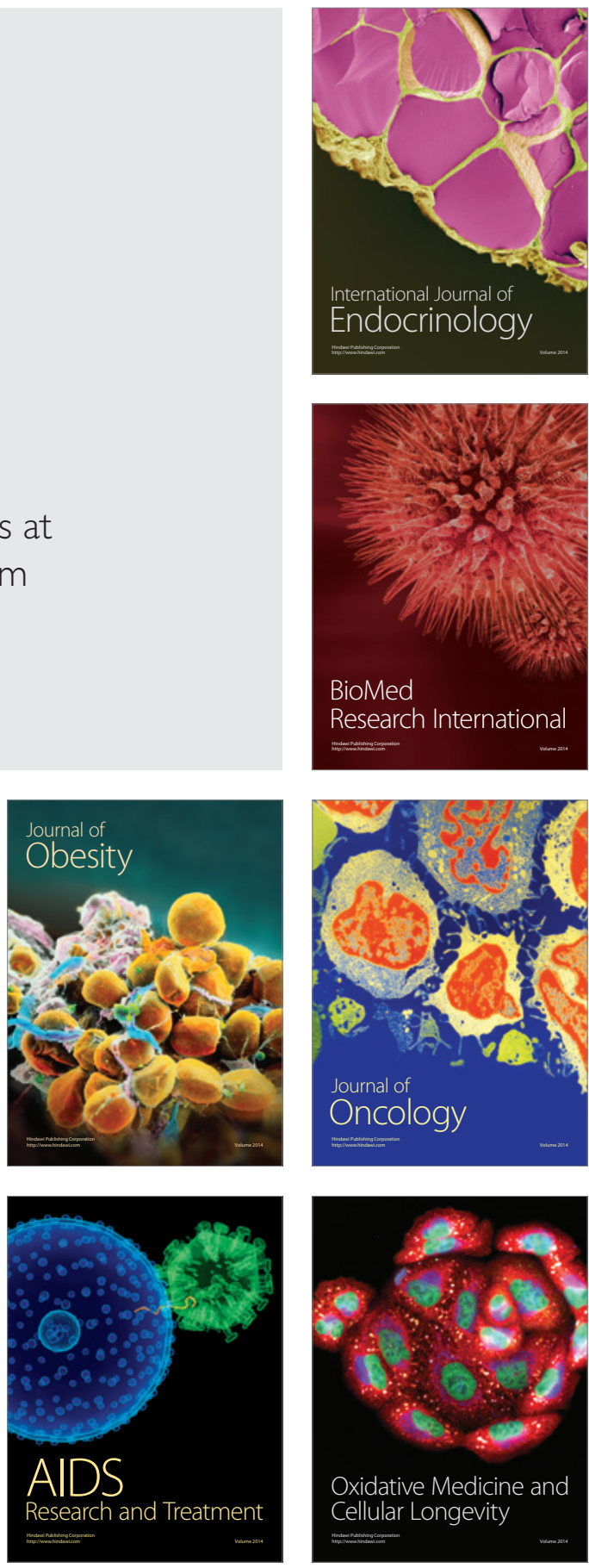